\title{
Regulatory effects of cAMP receptor protein (CRP) on porin genes and its own gene in Yersinia pestis
}

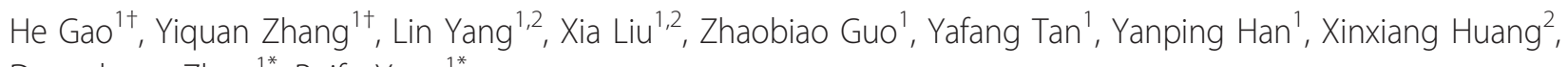
Dongsheng Zhou ${ }^{1 *}$, Ruifu Yang ${ }^{1^{*}}$

\begin{abstract}
Background: The CAMP receptor protein (CRP) is a global bacterial regulator that controls many target genes. The CRP-CAMP complex regulates the ompR-envZ operon in E. coli directly, involving both positive and negative regulations of multiple target promoters; further, it controls the production of porins indirectly through its direct action on ompR-envZ. Auto-regulation of CRP has also been established in E. coli. However, the regulation of porin genes and its own gene by CRP remains unclear in Y. pestis.

Results: Y. pestis employs a distinct mechanism indicating that CRP has no regulatory effect on the ompR-envZ operon; however, it stimulates $\mathrm{OmpC}$ and $\mathrm{ompF}$ directly, while repressing ompX. No transcriptional regulatory association between CRP and its own gene can be detected in $Y$. pestis, which is also in contrast to the fact that CRP acts as both repressor and activator for its own gene in E. coli. It is likely that $Y$. pestis OmpR and CRP respectively sense different signals (medium osmolarity, and cellular cAMP levels) to regulate porin genes independently.
\end{abstract}

Conclusion: Although the CRP of $Y$. pestis shows a very high homology to that of $E$. coli, and the consensus DNA sequence recognized by CRP is shared by the two bacteria, the $Y$. pestis CRP can recognize the promoters of $\mathrm{ompC}, F$, and $X$ directly rather than that of its own gene, which is different from the relevant regulatory circuit of $E$. coli. Data presented here indicate a remarkable remodeling of the CRP-mediated regulation of porin genes and of its own one between these two bacteria.

\section{Background}

The two major porins of Escherichia coli, namely OmpF and $\mathrm{OmpC}$, form non-specific transport channels and allow for the passive diffusion of small, polar molecules (such as water, ions, amino acids, and other nutrients, as well as waste products) across the cell membrane. High and low levels of OmpF and OmpC are respectively expressed at low osmolarities in E. coli; as the medium osmolarity increases, OmpF expression is repressed, while OmpC is activated $[1,2]$. OmpF forms a larger pore (hence a faster flux) than OmpC [3]. OmpC expression is favored when the enteric bacteria, such as

\footnotetext{
*Correspondence: dongshengzhou1977@gmail.com; ruifuyang@gmail.com + Contributed equally

'State Key Laboratory of Pathogen and Biosecurity, Beijing Institute of Microbiology and Epidemiology, Beijing 100071, PR China

Full list of author information is available at the end of the article
}

E. coli, live in the mammalian gut where a high osmolarity (300 $\mathrm{mM}$ of $\mathrm{NaCl}$ or higher) is observed; in addition, the smaller pore size of OmpC can aid in the exclusion of harmful molecules in the gut. OmpF can predominate in the aqueous habitats, and its larger pore size can assist in scavenging for scarce nutrients from the external aqueous environments.

OmpX represents the smallest known channel protein. OmpX expression in Enterobacter is inducible under high osmolarity, which is accompanied by the repressed expressions of OmpF and OmpC [4-6]. The overexpression of OmpX can balance the decreased expression of non-specific porins, $\mathrm{OmpF}$ and $\mathrm{OmpC}$, for the exclusion of small harmful molecules. However, whether or not OmpX functions as a porin to modulate the membrane permeability is still unclear.

\section{Biomed Central}

() 2011 Gao et al; licensee BioMed Central Ltd. This is an Open Access article distributed under the terms of the Creative Commons Attribution License (http://creativecommons.org/licenses/by/2.0), which permits unrestricted use, distribution, and reproduction in any medium, provided the original work is properly cited. 
The osmosensor histidine protein kinase EnvZ can phosphorylate the response regulator OmpR, which constitutes a two-component signal transduction and regulatory system. The reciprocal regulation of OmpF and OmpC in E. coli is mediated by phosphorylated OmpR (OmpR-P) [2,7,8] (Figure 1). OmpR-P binds to four (F4, F1, F2, and F3 from the 5' to 3' direction) and three $(\mathrm{C} 1, \mathrm{C} 2$, and $\mathrm{C} 3$ ) sites within the upstream regions of $o m p F$ and $o m p C$, respectively, with each containing two tandem 10 bp subsites ('a' and 'b') bound by two OmpR-P molecules. At low osmolarity, OmpR-P tandemly binds to F1 and F2 (and somewhat loosely to F3) in order to activate the transcription of $o m p F$; meanwhile OmpR-P occupies C1 but not $\mathrm{C} 2$ and $\mathrm{C} 3$, which is not sufficient to stimulate the transcription of ompC. With increasing osmolarity, the cellular levels of OmpR$\mathrm{P}$ elevate, and OmpR-P binds to $\mathrm{C} 2$ and $\mathrm{C} 3$ coopera-

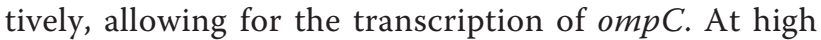
osmolarity, OmpR-P is also capable of binding to F4, which is a weak site upstream F1-F2-F3. Due to the tandem binding of OmpR-P on F4 and F1-F2-F3, the

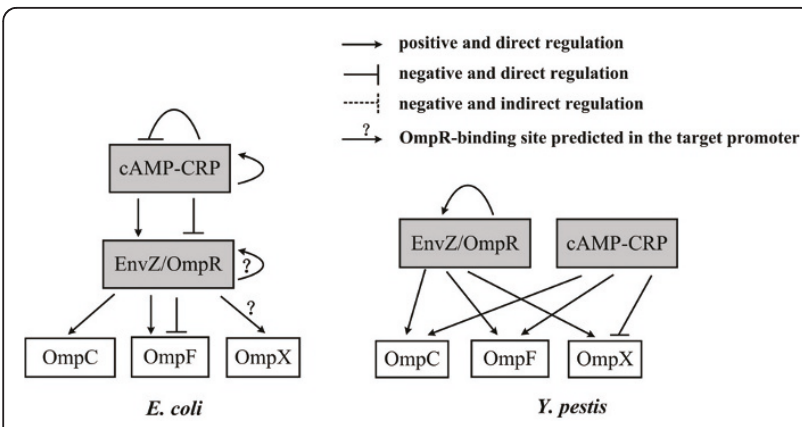

Figure 1 Comparison of porin regulation by OmpR and CRP in E. coli and $Y$. pestis. The OmpR-mediated reciprocal regulation of OmpF and OmpC in E. coli was discussed in the text $[2,7,8]$. In addition, CRP controlled the production of porins indirectly through its direct regulation of OmpR/EnvZ in E. coli $[8,15]$. As shown in this study, Y. pestis employs a distinct mechanism indicating that CRP has no regulatory effect on the ompR-envZ operon, although it stimulates $O m p C$ and $o m p F$ directly, while repressing ompX at the same time. It is likely that OmpR and CRP respectively sense different signals, medium osmolarity, and cellular CAMP levels to regulate porin genes independently. As shown previously [12], $Y$. pestis OmpR simulates $\mathrm{mpC}, F, X$, and $R$ directly by occupying the target promoter regions. Notably, all of ompF, $C, X$, and $R$ give a persistent and dramatic up-regulation with the increasing medium osmolarity in Y. pestis, which is dependent of OmpR. Upon the shifting of medium osmolarity, porin expression in $Y$. pestis is contrary to the reciprocal regulation of $\mathrm{OmpF}$ and $\mathrm{OmpC}$ in E. coli. The F1-F2-F3 and C1-C2-C3 sites are detected for ompF and ompC of $Y$. pestis, respectively. Remarkably, the F4 site is absent from the upstream region of ompF, which probably destroys the OmpRmediated blocking mechanism of ompF at high osmolarity. In E. coli, CRP acts as both repressor and activator for its own gene $[28,29]$. However, no transcriptional regulatory association between CRP and its own gene was detected in $Y$. pestis. upstream DNA of $o m p F$ forms a circular loop, effectively blocking the $o m p F$ transcription.

OmpR contributes to the building of resistance against phagocytosis and survival within macrophages, which is likely conserved in all the pathogenic yersiniae, namely, $Y$. enterocolitica $[9,10], Y$. pseudotuberculosis [11], and $Y$. pestis [12]. However, in contrast to $Y$. enterocolitica and $Y$. pseudotuberculosis, the virulence of $Y$. pestis is likely unaffected by the ompR null mutation. $Y$. pestis OmpR directly regulates $\operatorname{omp} C, F, X$, and $R$ through OmpR-promoter DNA association (Figure 1). High osmolarity induces the transcription of all the porin genes $(o m p F, C$, and $X)$ in $Y$. pestis, in contrast with their reciprocal regulation in $E$. coli. The major difference is that $o m p F$ transcription is not repressed at high osmolarity in $Y$. pestis, which is likely due to the absence of a promoter-distal OmpR-binding site for $o m p F$.

cAMP Receptor Protein (CRP) is a global regulator, which controls a large array of target genes [13,14]. CRP binds to its sole cofactor cAMP to form the CRP-cAMP complex for binding to specific DNA sequence within the target promoters [13]. CRP-cAMP activates transcription by binding to specific sites, often upstream of the core promoter ( -10 and -35 elements), where it directly interacts with RNA polymerase; it also represses the expression of a few genes where the binding site overlaps with or downstream the core promoter. The CRP-cAMP consensus binding site is TGTGA-N6TCACA, and variations on this consensus sequence can influence the affinity of CRP-CAMP to bind to different sites, resulting in the regulation of different operons by CRP-cAMP. Meanwhile, cAMP is synthesized from ATP by adenylyl cyclase encoded by cyaA. CRP-cAMP regulates the ompR-envZ operon in E. coli directly, involving both positive and negative regulation of multiple ompRenvZ promoters [15]. On the other hand, it controls the production of porins indirectly through its direct regulation of EnvZ/OmpR in E. coli (Figure 1).

CRP is a virulence-required regulator of several bacterial pathogens, including $Y$. pestis $[16,17]$. The $c r p$ disruption in $Y$. pestis leads to a much greater loss of virulence by subcutaneous infection relative to intravenous inoculation [16]. CRP directly stimulates the expression of plasminogen activator $[16,18]$, a key virulence factor essential for bubonic and primary pneumonic plague $[19,20]$, while directly repressing the sycO-ypkA-yopJ operon encoding the chaperone SycO and the effectors YpkA and YopJ of the plasmid pCD1borne type III secretion system [21].

This study discloses that $Y$. pestis employs a distinct mechanism indicating that CRP has no regulatory effect on the ompR-envZ operon, although it stimulates $\operatorname{ompC}$ and $o m p F$ directly, while repressing $o m p X$ at the same time (Figure 1). In addition, no transcriptional 
regulatory association between CRP and its own gene could be detected in $Y$. pestis, which is also related to the fact that CRP acted as both repressor and activator for its own gene in E. coli. It is likely that $Y$. pestis OmpR and CRP respectively sensed different signals, namely medium osmolarity, and cellular cAMP levels, to regulate porin genes independently.

\section{Methods}

\section{Bacterial strains}

The wild-type (WT) Y. pestis biovar microtus strain 201 is avirulent to humans but highly lethal to mice [22]. The base pairs 43 to 666 of ompR (720 bp in total length) or the entire region of $c r p$ was replaced by the kanamycin resistance cassette, to generate the $Y$. pestis $o m p R$ and crp null mutants. These mutants were designated as $\Delta o m p R$ [12] and $\Delta c r p[16,21]$, respectively. All the DNA sequences mentioned in this study were derived from the genomic data of CO92 [23]. The construction of the complemented mutant strain C-crp was also described in a previous work [16]. All the primers used in this study, which were designed using the Array Designer 3.0 or Primer Premier 5.0 software, were listed in Additional File 1.

\section{Bacterial growth and RNA isolation}

Overnight cultures (an $\mathrm{OD}_{620}$ of about 1.0) of WT, $\Delta c r p$ or $\Delta o m p R$ in the chemically defined TMH medium [24] were diluted into the fresh TMH with a 1:20 ratio. Bacterial cells were grown at $26^{\circ} \mathrm{C}$ to the middle exponential growth phase (an $\mathrm{OD}_{620}$ of about 1.0). To trigger the high osmolarity conditions in OmpR-related experiments, a final concentration of $0.5 \mathrm{M}$ sorbitol was added [25], after which the cell cultures were allowed to grow for an additional $20 \mathrm{~min}$. For all CRP-related in vivo experiments, $1 \mathrm{mM}$ cAMP acting as the activator of CRP was added into the fresh TMH medium [16,21].

Total RNA from bacterial cells was extracted using the TRIzol Reagent (Invitrogen) without DNA removing step (for RT-PCR and primer extension) or by using

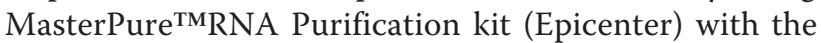
removal of contaminated DNA (for microarray) [16,21]. Immediately before harvesting, bacterial cultures were mixed with RNAprotect Bacteria Reagent (Qiagen) to minimize RNA degradation. RNA quality was monitored by agarose gel electrophoresis, and RNA quantity was determined using a spectrophotometer.

\section{Quantitative RT-PCR}

Gene-specific primers were designed to produce a 150 to $200 \mathrm{bp}$ amplicon for each gene. The contaminated DNA in RNA samples was removed using the Amibion's DNA-free ${ }^{\mathrm{TM}}$ Kit. cDNAs were generated using $5 \mu \mathrm{g}$ of RNA and $3 \mu \mathrm{g}$ of random hexamer primers. Using 3 independent cultures and RNA preparations, quantitative RT-PCR was performed in triplicate as described previously through the LightCycler system (Roche) together with the SYBR Green master mix [16,21]. The PCR reaction mixture contained $2 \mu \mathrm{l}$ of $10 \times$ PCRbuffer, $2 \mu \mathrm{l}$ of $25 \mathrm{mmol} / \mathrm{l} \mathrm{MgCl}_{2}, 0.4 \mu \mathrm{l}$ of $5 \mathrm{U} / \mu \mathrm{l}$ ExTaq DNA polymerase (Takala), $1 \mu \mathrm{l}$ of 1:500 SYBR Green I, $0.3 \mu \mathrm{l}$ of each primer $(10 \mu \mathrm{mol} / \mathrm{l}), 0.16 \mu \mathrm{l}$ of $10 \mathrm{mmol} / \mathrm{l} \mathrm{dNTP}$, and $2 \mu \mathrm{l}$ of cDNA templates, with the addition of $\mathrm{H}_{2} \mathrm{O}$ to arrive at a total volume of $20 \mu \mathrm{l}$. After pre-denaturation at $95^{\circ} \mathrm{C}$ for $3 \mathrm{~min}$ at a temperature transition rate of $20^{\circ} \mathrm{C} / \mathrm{s}$, PCR amplification was conducted at 45 cycles of denaturation at $95^{\circ} \mathrm{C}$ for $2 \mathrm{~s}$ at $20^{\circ} \mathrm{C} / \mathrm{s}$, annealing at $58^{\circ} \mathrm{C}$ for $4 \mathrm{~s}$ at $20^{\circ} \mathrm{C} / \mathrm{s}$ and extension at $72^{\circ} \mathrm{C}$ for $8 \mathrm{~s}$ at $20^{\circ} \mathrm{C} / \mathrm{s}$, after which a single fluorescence measurement was taken at the end of the extension step. After amplification, a final melting curve was recorded by heating to $95^{\circ} \mathrm{C}$, cooling to $65^{\circ} \mathrm{C}$ at $20^{\circ} \mathrm{C} / \mathrm{s}$, followed by a $60 \mathrm{~s}$ holding period at $65^{\circ} \mathrm{C}$ before heating slowly at $0.2^{\circ} \mathrm{C} /$ sec to $95^{\circ} \mathrm{C}$. On the basis of the standard curves of $16 \mathrm{~S}$ rRNA expression, the relative mRNA level was determined by calculating the threshold cycle $(\Delta \mathrm{Ct})$ of each gene using the classic $\Delta \mathrm{Ct}$ method. Negative controls were performed using 'cDNA' generated without reverse transcriptase as templates. Reactions containing primer pairs without template were also included as blank controls. The $16 \mathrm{~S}$ rRNA gene was used as an internal control to normalize all the other genes [16]. The transcriptional variation between the WT and mutant strain was calculated for each gene. A mean ratio of two was taken as the cutoff of statistical significance.

\section{Primer extension assay}

For the primer extension assay [16,21], about $10 \mu \mathrm{g}$ of total RNA from each strain was annealed with 1 pmol of $\left[\gamma_{-}{ }^{32} \mathrm{P}\right]$ end-labeled reverse primer. The extended reverse transcripts were generated as described in the protocol for Primer Extension System-AMV Reverse Transcriptase (Promega). The yield of each primer extension product would indicate the mRNA expression level of the corresponding gene in the corresponding strain, and further could be employed to map the 5' terminus of RNA transcript for each gene. The same labeled primer was also used for sequencing with the fmol ${ }^{\circledR}$ DNA Cycle Sequencing System (Promega). The primer extension products and sequencing materials were concentrated and analyzed using $8 \mathrm{M}$ urea-6\% polyacrylamide gel electrophoresis. The result was detected by autoradiography (Kodak film).

\section{LacZ reporter fusion and $\beta$-Galactosidase assay}

The 500 to 600 bp upstream DNA region of each indicated gene (Table 1) was obtained by PCR with the ExTaq ${ }^{\mathrm{TM}}$ DNA polymerase (Takara) using Y. pestis 201 
Table 1 Genes tested in both computational and biochemical assays

\begin{tabular}{|c|c|c|c|c|c|c|c|}
\hline \multirow[t]{2}{*}{ Gene ID } & \multirow[t]{2}{*}{ Gene } & \multirow[t]{2}{*}{ Regulation } & \multicolumn{3}{|c|}{ Computational matching of regulatory consensus } & \multicolumn{2}{|c|}{ Position of DNA fragment used ${ }^{\S}$} \\
\hline & & & Position§ & Sequence & Score & LacZ & Footprinting \\
\hline YPO1222 & ompC & + & R-191...-169 & AAACAGTGAGTTATAGCACATAT & 12.3 & $-379 \ldots+130$ & $-281 \ldots-26$ \\
\hline YPO1411 & ompF & + & D-131...-109 & ACTTTGGACTTAGATCGAATTT & 10.73 & $-328 \ldots+143$ & $-237 \ldots-4$ \\
\hline YPO2506 & ompX & - & D-156...-134 & AGTATGTGACCTCCATCACCCAA & 11.68 & $-374 \ldots+123$ & $-321 \ldots+4$ \\
\hline YPO0136 & ompR & NO & - & - & 0 & $-409 \ldots+83$ & $-409 \ldots+83$ \\
\hline YPO0175 & $c r p$ & NO & $R+235 \ldots+257$ & GAACTCTGAGCCCTGTTAAGTTA & 1.44 & $-147 \ldots+344$ & $-147 \ldots+344$ \\
\hline
\end{tabular}

$\S$, The numbers indicate the nucleotide positions upstream of the transcription start sites.

+ , positive and direct regulation.

- , negative and direct regulation.

genome DNA as the template. PCR fragments were then cloned directionally into the EcoRI and BamHI sites of plasmid pRW50 that harbors a tetracycline resistance gene and a promotorless lac $Z$ reporter gene [26]. Correct cloning was verified by DNA sequencing. $Y$. pestis was transformed with the recombinant plasmids and grown as described in microarray analysis. The empty plasmid pRW50 was also introduced into both strains as negative control. $\beta$-Galactosidase activity was measured on cellular extracts using the $\beta$-Galactosidase Enzyme Assay System (Promega) [16,21]. Assays were performed in triplicate. A mean value of two-fold change was taken as the cutoff of statistical significance.

\section{Preparation of His-OmpR and His-CRP proteins}

The entire coding region of ompR or $c r p$ was amplified from $Y$. pestis 201 and then cloned directionally into the BamHI and HindIII sites of plasmid pET28a, which was verified by DNA sequencing $[16,21]$. The recombinant plasmid encoding a His-protein was transformed into

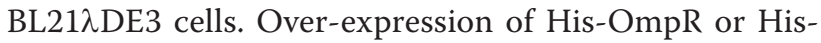
CRP in the LB medium was induced by adding $1 \mathrm{mM}$ IPTG (isopropyl-b-D-thiogalactoside). The overexpressed proteins were purified under native conditions with nickel loaded HiTrap Chelating Sepharose columns (Amersham). The purified and eluted proteins were concentrated to a final concentration of 0.1 to $0.3 \mathrm{mg} / \mathrm{ml}$ with the Amicon Ultra-15 (Millipore), which was confirmed by SDS-PAGE for purity. The purified proteins were stored at $-80^{\circ} \mathrm{C}$ until further use.

\section{DNase I footprinting}

The promoter DNA region (Table 1) was prepared by PCR amplification performed with the promoter-specific primer pairs, including a $5^{\prime}-32 \mathrm{P}$-labeled primer (either forward or reverse) and its non-labeled counterpart. The PCR products were purified using QiaQuick cleanup columns (Qiagen). Increasing amounts of purified Hisprotein were incubated with the labeled DNA fragment ( 2 to $5 \mathrm{pmol}$ ) for $30 \mathrm{~min}$ at room temperature in a binding buffer containing $10 \mathrm{mM}$ Tris- $\mathrm{Cl}$ (pH7.4), $50 \mathrm{mM}$
$\mathrm{KCl}, 0.5 \mathrm{mM}$ DTT, $1 \mathrm{mM} \mathrm{MgCl}_{2}$, 4 glycerol, $0.05 \mathrm{mg} /$ $\mathrm{ml} \mathrm{BSA}, 0.05 \mathrm{mg} / \mathrm{ml}$ shared salmon sperm DNA and 0.5 mM EDTA, with a final volume of $10 \mu \mathrm{l}[16,21]$. To achieve the OmpR phosphorylation, $25 \mathrm{mM}$ fresh acetyl phosphate was added in the binding buffer and incubated with purified His-OmpR for $30 \mathrm{~min}$, after which the labeled DNA was added for additional incubation for $30 \mathrm{~min}$. To activate CRP, $2 \mathrm{mM}$ cAMP was mixed with purified His-CRP in the DNA-binding reactions. To initiate DNA digestion, $10 \mu \mathrm{l}$ of $\mathrm{Ca}^{2+} / \mathrm{Mg}^{2+}$ solution (5 $\mathrm{mM} \mathrm{CaCl} 2$ and $10 \mathrm{mM} \mathrm{MgCl}$ ) was added, followed by incubation for $1 \mathrm{~min}$ at room temperature. Afterwards, the optimized RQ1 RNase-Free DNase I (Promega) was added to the reaction mixture, and the mixture was incubated at room temperature for 30 to $90 \mathrm{~s}$. The cleavage reaction was stopped by adding $9 \mu \mathrm{l}$ of the stop solution $(200 \mathrm{mM} \mathrm{NaCl}, 30 \mathrm{mM}$ EDTA, and $1 \%$ SDS) followed by DNA extraction and precipitation. The partially digested DNA samples were then analyzed in a $6 \%$ polyacrylamide/ $8 \mathrm{M}$ urea gel. Protected regions were identified by comparing these with the sequence ladders. For sequencing, the fmol ${ }^{\circledR}$ DNA Cycle Sequencing System (Promega) was used, and the final result was detected by autoradiography (Kodak film).

\section{Computational promoter analysis}

The $300 \mathrm{bp}$ promoter regions upstream of the start codon of each indicated gene was retrieved using the 'retrieve-seq' program [27]. The 'matrices-paster' tool [27] was used to match the relevant position-specific scoring matrix (PSSM) within the above promoter regions.

\section{Results}

Non-polar mutation of ompR or crp

The ompR and $c r p$ null mutants designated as $\Delta o m p R$ and $\Delta c r p$, respectively, have been evaluated in the present study. Non-polar mutation of $\mathrm{ompR}$ has been confirmed previously with the complemented $o m p R$ mutant [12]. To prove the non-polar mutation of crp, we constructed the pRW50-harboring fusion promoter, which 
consisted of a promoter-proximal region of $o m p F$ and promoterless lacZ, and then transformed into WT, $\Delta c r p$ and C-crp (the complemented crp mutant), respectively (Additional file 2). The $o m p F$ gene was positively regulated by CRP as determined by several distinct methods (see below). As expected, the ompF promoter activity ( $\beta$-galactosidase activity) decreased significantly in $\Delta c r p$ relative to WT grown in the TMH medium with the addition of $1 \mathrm{mM}$ cAMP, but showed almost no difference between WT and C-crp.

\section{Direct regulation of ompC, $\mathrm{F}$ and $\mathrm{X}$ by $\mathrm{CRP}$}

The quantitative RT-PCR analysis was also performed to compare the mRNA levels of each gene tested in $\Delta$ crp and WT in the presence of $1 \mathrm{mM}$ cAMP. Both RT-PCR (Figure 2a) and lac $Z$ fusion reporter (Figure $2 \mathrm{~b}$ ) assays revealed that the expression of $\operatorname{omp} C$ or $F$ decreased significantly in $\Delta c r p$ relative to WT, while that of $o m p X$ increased.

In addition, primer extension experiments (Figure 1c) were conducted for $\operatorname{omp} C, F$, and $X$ to detect the yield of primer extension product that represented the relative activity of each target promoter in $\Delta c r p$ or WT. A single promoter was transcribed for $o m p F$ or $X$, which was dependent on CRP. No primer extension product could be detected for ompC in both $\triangle o m p R$ and WT after repeated efforts, which might be due to the limitation of the primer extension assay. Meanwhile, the

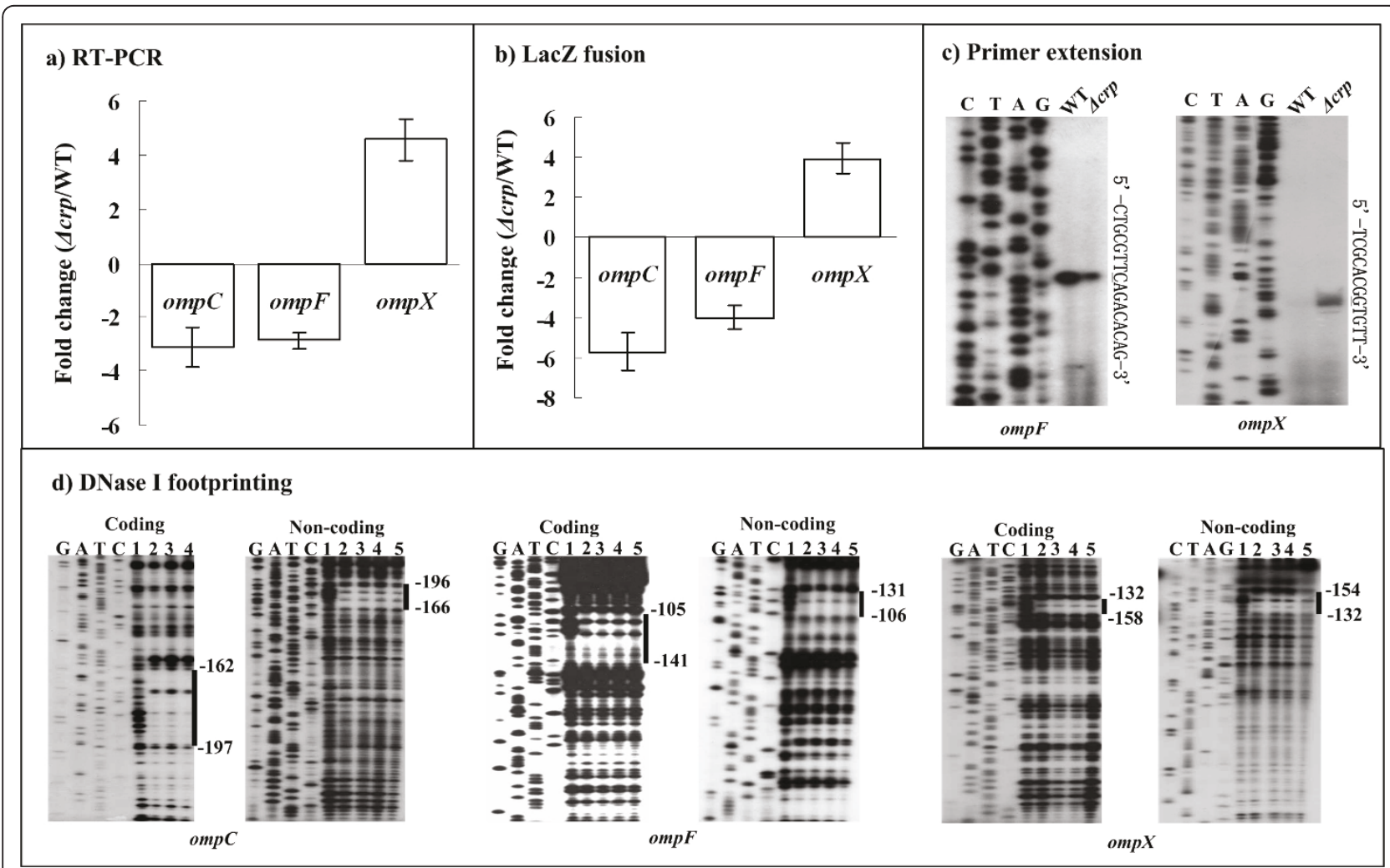

Figure 2 Regulation of $\boldsymbol{o m p C}, \boldsymbol{F}$ and $\boldsymbol{X}$ by CRP. a) Quantitative RT-PCR. The mRNA levels of each indicated gene were compared between $\Delta c r p$ and WT. This figure shows the increased (positive number) or decreased (minus one) mean fold for each gene in $\Delta c r p$ relative to WT. $\mathbf{b}$ ) LacZ fusion reporter. A promoter-proximal region of each indicated gene was cloned into pRW50 containing a promotorless lacZ reporter gene, and transformed into WT or $\Delta c r p$ to determine the promoter activity ( $\beta$-Galactosidase activity in cellular extracts). The empty plasmid was also introduced into the corresponding strain as negative control, which gave extremely low promoter activity (data not shown). $\beta$-Galactosidase activity in each tested cellular extract was subtracted with that of negative control. This figure shows the increased (positive number) or decreased (minus one) mean fold for the detecting promoter activity in $\Delta c r p$ relative to WT. c) Primer extension. Primer extension assays were performed for each indicated gene using total RNAs isolated from the exponential-phase of WT or $\Delta c r p$. An oligonucleotide primer complementary to the RNA transcript of each gene was designed from a suitable position. The primer extension products were analyzed with 8 M urea-6\% acrylamide sequencing gel; lanes C, T, A, and G represent the Sanger sequencing reactions, respectively. On the right side, DNA sequences are shown from the bottom (5') to the top ( $\left.3^{\prime}\right)$, and the transcription start sites were underlined. d) DNase I footprinting. The labeled DNA probe was incubated with various amounts of purified His-CRP (lanes 1, 2, 3, 4, and 5 containing 0, 5, 10, 15 and 20 pmol, respectively) in the presence of $2 \mathrm{mM}$ cAMP, and subjected to DNase I footprinting assay; lanes $G, A$, T, and C represent the Sanger sequencing reactions, respectively. The protected regions (bold lines) are indicated on the right-hand side. The numbers indicated the nucleotide positions upstream the transcriptional start sites. 
transcriptional levels of $o m p F$ or $X$ in $\triangle o m p R$ and WT, determined by primer extension experiments herein (Figure 1c), was consistent with the RT-PCR and lacZ fusion reporter data.

A previously described CRP consensus (PSSM) of $Y$. pestis [16] was used to scan the 300bp upstream DNA regions of $\operatorname{omp} C, F$ and $X$, with a cutoff score value of 7; CRP consensus-like sequences were also predicted for $o m p C, F$, and $X$ (Table 1 ). As determined by DNase I footprinting (Figure 2d), a purified His-CRP protein in the presence of $2 \mathrm{mM}$ cAMP protected a single distinct region upstream of each target gene against DNase I digestion in a dose-dependent pattern.

Taken together, CRP-cAMP stimulated $\operatorname{omp} C$ and $o m p F$, while repressing ompX through the CRP-promoter DNA association in $Y$. pestis.

\section{No autoregulation of CRP}

Both lacZ fusion reporter (Figure 3a) and primer extension (Figure $3 \mathrm{~b}$ ) assays showed almost the same levels of crp expression in both WT and $\Delta c r p$; moreover, the footprinting analysis (Figure 3c) indicated no direct association between His-CRP and crp promoter region in the presence $2 \mathrm{mM}$ cAMP. Thus, no transcriptional auto-regulation of CRP could be detected in $Y$. pestis under the growth conditions used in this work.

\section{No regulatory interaction between OmpR and CRP}

As determined by both primer extension and lac $Z$ fusion reporter assays, the $\operatorname{omp} R$ gene was expressed at almost the same level in both WT and $\Delta$ crp; likewise, no difference in the crp expression was observed between WT and $\triangle o m p R$ (Figure 4). Moreover, the footprinting analysis indicated no direct association between the
His-CRP protein and the $o m p R$ promoter region or between the His-OmpR-P protein and the crp promoter region (Figure 4). Accordingly, under the growth conditions used in this work, OmpR had no regulatory effect on crp, and in turn, CRP did not regulate ompR.

\section{Structure of promoter-proximal regions}

The footprint regions determined by DNase I footprinting were considered as the binding sites of relevant regulators. The primer extension product could be used to map the 5' terminus of RNA transcript of each gene tested, allowing for the determination of transcriptional start sites and localization of the core promoter region $(-10$ and -35 elements). Considering the data here and those described previously [12], we depicted OmpR- or CRP-binding sites, transcriptional start sites, and -10/-35 elements within the promoter-proximal regions of $\operatorname{omp} C, F, X$ and $R$ (Figure $5)$, resulting in a map of regulator-promoter DNA association for mediating transcriptional regulation. Since we failed to detect the 5 ' terminus of the RNA transcript for отр $C$ using primer extension assay, a transcriptional start site was predicted for this gene with the NNPP tool http:// searchlauncher.bcm.tmc.edu/seq-search/gene-search.html. The results showed that a single distinct promoter was transcribed for all the four genes, and the detecting promoters for ompC, $F$, and $X$ were dependent on both OmpR and CRP, while that of $o m p R$ was regulated by its own protein product but not by CRP. A single distinct OmpR- or CRP-binding site was respectively detected in $o m p C, F$, and $X$, all of which were upstream of the promoter - 35 elements. The detecting OmpR- and CRP-binding sites contained the corresponding consensus-like sequences as predicted by computational promoter analysis.

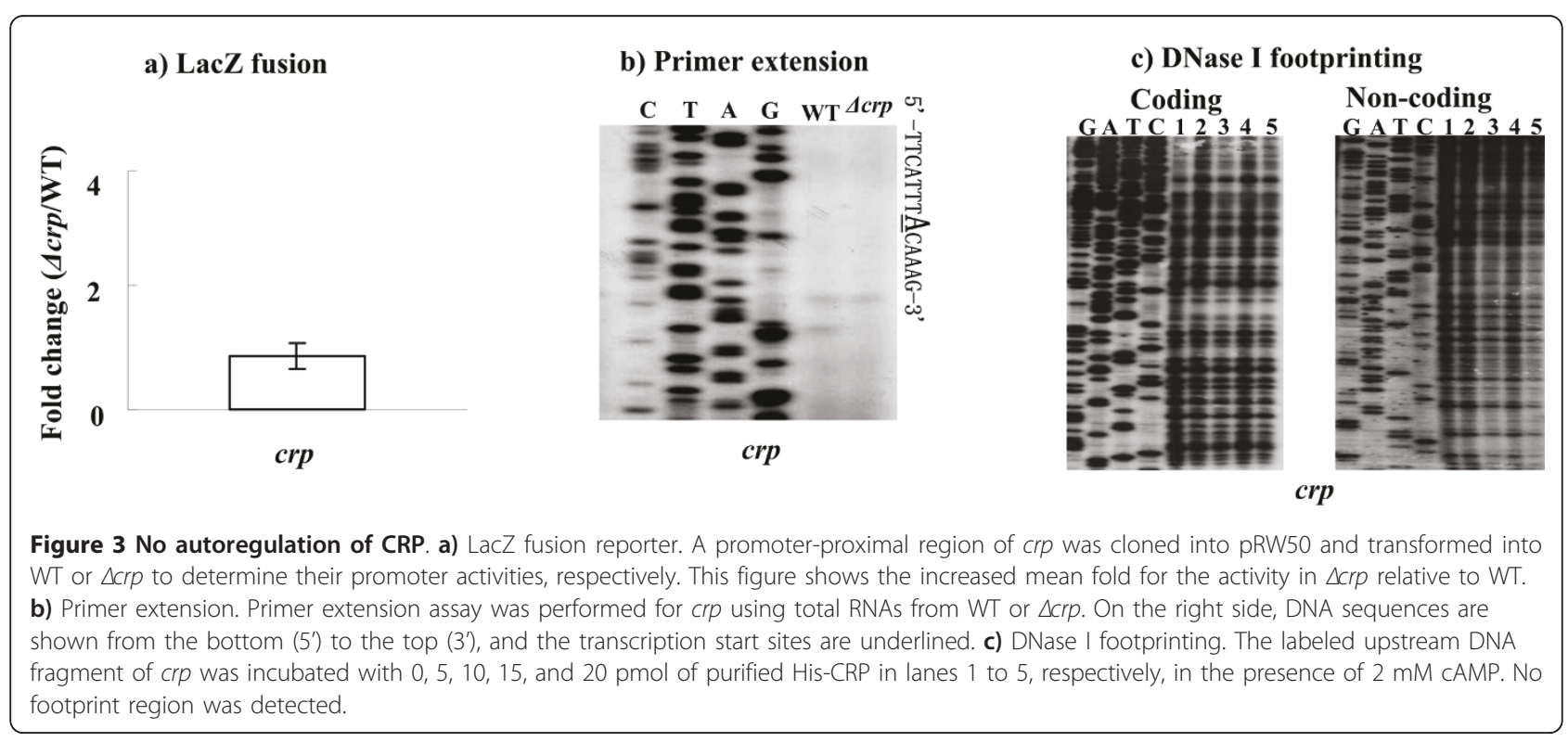




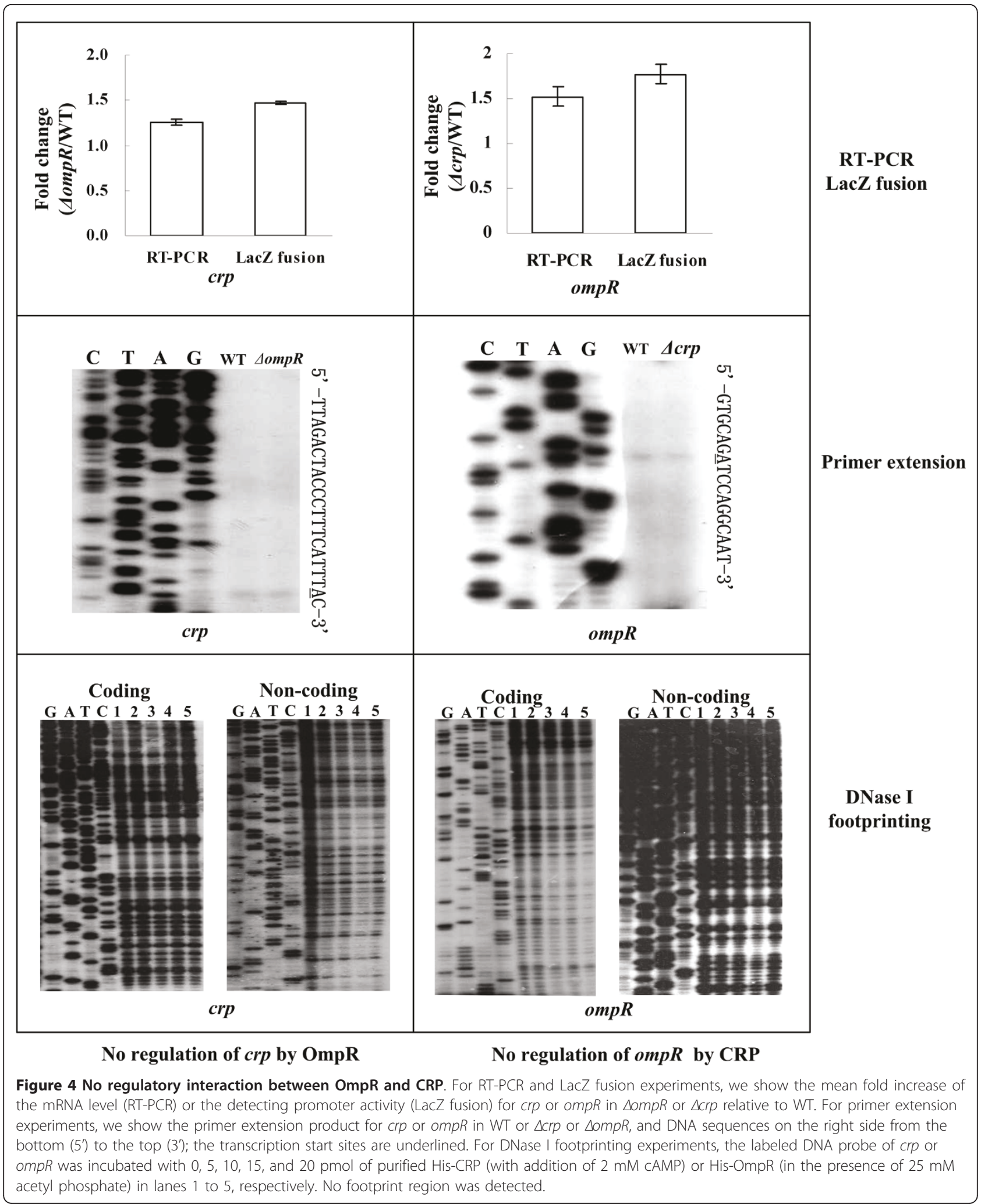




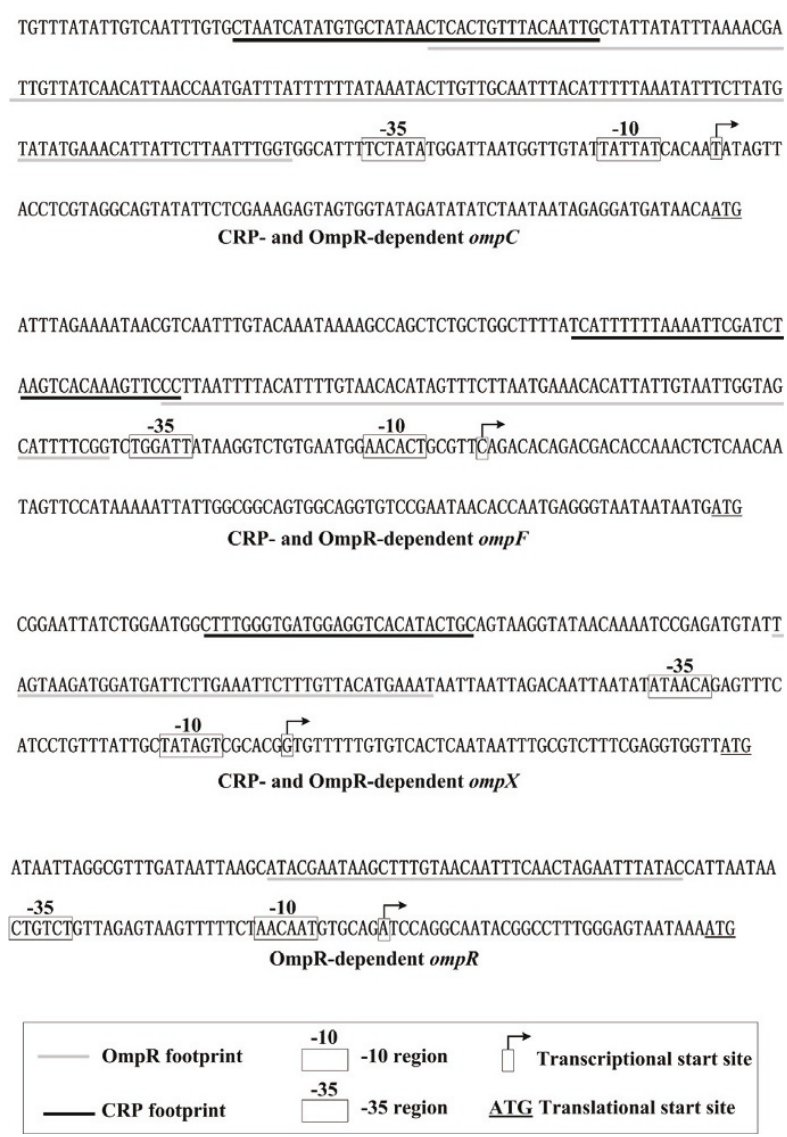

Figure 5 Promoter structure for $\operatorname{ompC}, F, X$ and $\boldsymbol{R}$. The start codon (ATG) of each gene is shown at the $3^{\prime}$ terminus. The nucleotide number corresponding to the transcription start site was taken as " +1 ", from which the promoter -10 and-35 elements were predicted accordingly. Data of OmpR-promoter DNA association came from the previous data [12].

\section{No interplay of OmpR and CRP at target promoters}

There was no overlapping of OmpR- and CRP-binding sites for ompX; however, overlapping regions that were 17 and $2 \mathrm{bp}$ in length were observed for $o m p C$ and $o m p F$, respectively. We performed further footprinting experiments using the coding strands of the promoterproximal DNA fragments of $\operatorname{omp} C, F$, and $X$ with different amounts of OmpR and CRP in various reactions (Figure 6). His-CRP protected each promoter region tested in a dose-dependent manner when His-OmpR-P was at the highest amount (20 pmol), and vice versa. Both His-CRP and His-OmpR-P at the highest amounts were able to bind together to each promoter region tested. These results indicated that no competitive binding occurred between them to these target promoters. It was likely that OmpR and CRP sensed different signals to regulate $\operatorname{omp} C, F$, and $X$ in an independent manner.

\section{Discussion}

\section{Autoregulation of CRP-CAMP}

In $E$. coli, CRP acts as both repressor and activator for its own gene $[28,29]$, while also repressing the cyaA expression [30]. Enteric bacteria catabolize other sugars only when the supply of glucose has become depleted, whereas the presence of glucose prevents the bacteria from catabolizing alternative sugars, which is referred to as catabolite repression mainly mediated by CRP-cAMP for positively controlling the metabolism of alternative sugars $[13,14]$. A mode for the regulation of the CRPcAMP machinery during catabolite repression could be established in $E$. coli as follows [28,29,31,32]: i) the presence of glucose (catabolite repression) reduces the cAMP level by decreasing the phosphorylated form of enzyme IIAGlc, which is involved in the activation of CyaA, after which the reduction of cAMP can affect the positive autoregulatory mechanism of $\operatorname{crp}$ (see below) to cause a further decrease of crp expression; and ii) once at cAMP-rich conditions (e.g., the replacement of glucose by mannitol), CRP-cAMP activates the crp transcription by occupying the CRP binding site II, after whichthe elevated expression of CRP-cAMP enables its recognition of the CRP binding site I located $40 \mathrm{bp}$ downstream the crp transcription start site (thereby preventing the occupation of RNA polymerase at the crp promoter), while repressing the cyaA transcription; and finally, a return to basal levels of CRP and cAMP is induced.

It is noteworthy that transcriptional regulatory association between CRP and its own gene can be detected in $Y$, pestis. However, CRP bound to a DNA region that overlapped the promoter -10 region of $c y a A$, can block the entry of the RNA polymerase for repressing the transcription of cyaA in $Y$. pestis (data unpublished). Since the cyaA-encoding adenylyl cyclase is a key enzyme catalyzing the synthesis of cAMP, which is the sole essential cofactor of CRP, repression of cAMP production by CRP represents a mechanism for negative modulation of cellular CRP function.

\section{CRP-CAMP and osmoregulation}

The cellular cAMP levels are significantly increased at high osmolarity relative to low osmolarity in E. coli; this osmoregulation requires the cAMP molecule, and is mainly exerted at the transcriptional level although the control at the posttranscriptional level cannot be excluded [33]. The replacement of glucose by other catabolites in the medium triggers the elevation of both cAMP and CRP levels in $E$. coli $[32,34]$, resulting in the increase and decrease of $\mathrm{OmpF}$ and $\mathrm{OmpC}$ levels, respectively [8]. OmpF allows a higher number of compounds to enter the cell than the more restrictive OmpC channel, thereby contributing to the transport of amino acids as a secondary 


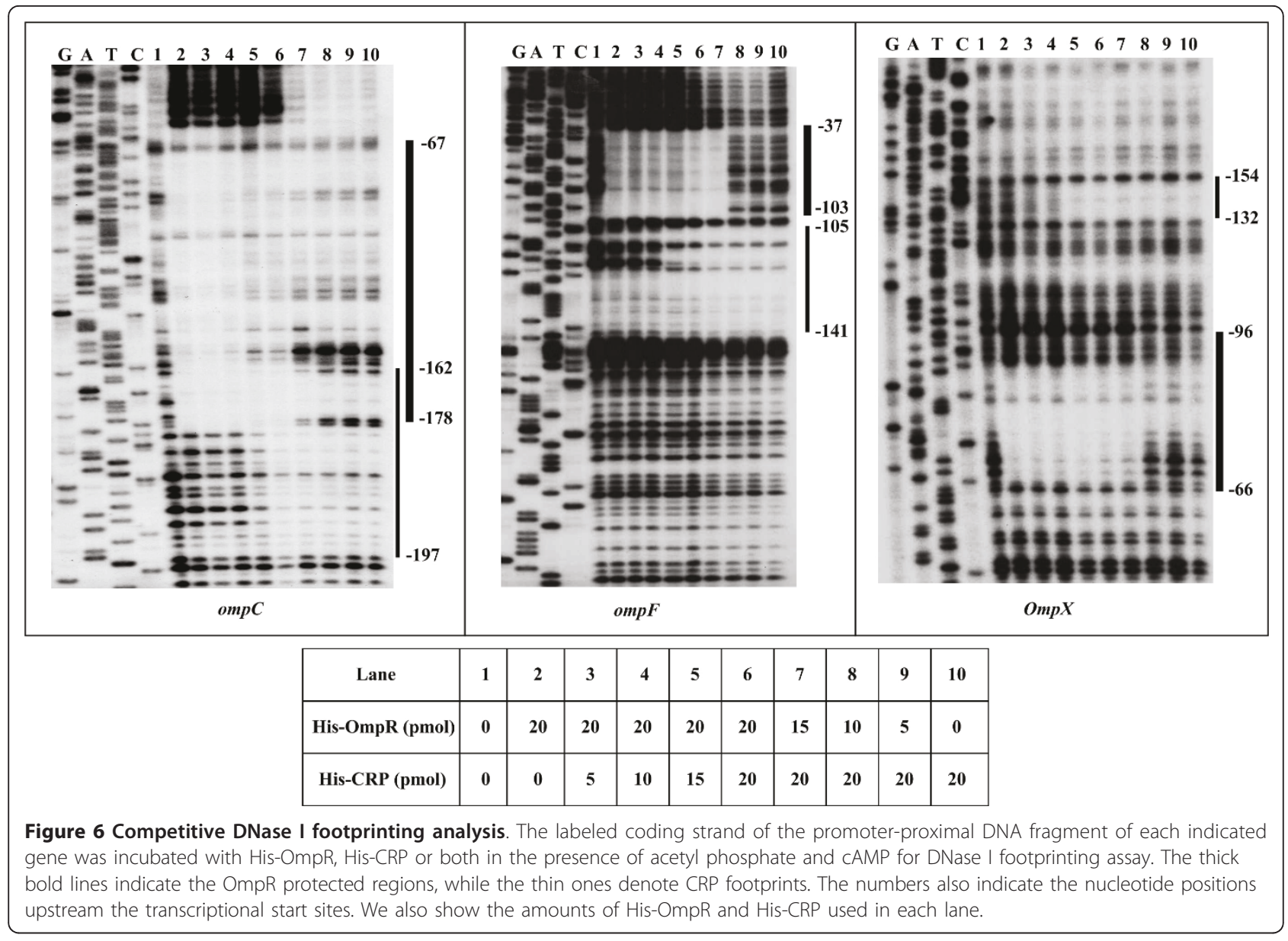

carbon/energy source for $E$. coli in the absence of glucose [15]. CRP-cAMP directly regulates the ompR-envZ operon in $E$. coli through the process of binding to a single site within the upstream region of ompR [15]. Four transcripts were detected for the ompR-envZ operon, while CRPcAMP negatively regulates the two promoters that overlap the CRP binding site and is positive for the other two that are located further downstream from this site [15]. Thus, CRP-cAMP controls the production of porins indirectly through its direct action on ompR-envZ in E. coli. In contrast, $Y$. pestis has evolved a distinct mechanism, wherein CRP-cAMP has no regulatory effect on the ompR-envZ operon; rather, consistent with the findings reported here, it directly stimulates $o m p C$ and $o m p F$, while repressesing ompX. Regulation of ompX by CRP through the CyaR small RNA has been established in both Salmonella enterica [35] and E. coli [36,37]; the CRP-cAMP complex is a direct activator of the transcription of CyaR, which further promotes the decay of the $\mathrm{omp} X \mathrm{mRNA}$, under conditions in which the cAMP levels are high. Transcription of the P1 promoter of the E. coli proP gene, which encodes a transporter of osmoprotectants (proline, glycine betaine, and other osmoprotecting compounds) is strongly induced by a shift from low to high osmolarity conditions $[38,39]$. CRP-cAMP functions as an osmosensitive repressor of the proP P1 transcription through CRP-cAMP-promoter DNA association $[38,39]$. The proP $\mathrm{P} 2$ promoter is induced upon entry into the stationary phase to protect cells from osmotic shock; the CRP-cAMP and Fis regulators synergistically coactivate the $\mathrm{P} 2$ promoter activity, through independently binding to two distinct P2 promoter-proximal regions and making contacts with the two different $\mathrm{C}$-terminal domains of the a subunit of RNA polymerase [40]. These findings suggest that CRP-cAMP functions in certain contexts in osmoregulation of gene expression, in addition to its role in catabolite control.

\section{Remodeling of regulatory circuits of porin genes}

The evolutionary remodeling of regulatory circuits can bring about phenotypic differences between related organisms [41]. This is of particular significance in bacteria due to the widespread effects of horizontal gene transfer. A set of newly acquired virulence genes (e.g., pla and the $\mathrm{pH} 6$ antigen genes) in $Y$. pestis has evolved to integrate themselves into the 'ancestral' CRP or RovA regulatory cascade $[16,18,42]$. The $\mathrm{PhoP}$ regulons have 
been extensively compared in $Y$. pestis and $S$. enterica $[41,43]$. The orthologous PhoP proteins in these bacteria differ both in terms of their ability to promote transcription and in their role as virulence regulators. The core regulon controls the levels of active PhoP protein and mediates the adaptation to low $\mathrm{Mg}^{2+}$ conditions. In contrast, the variable regulon members contribute speciesspecific traits that allow the bacteria to incorporate newly acquired genes into their ancestral regulatory circuits [41,43]. In general, $Y$. pestis integrates virulence genes acquired laterally to coordinate their expressions within its regulatory backbone cascades to maintain the homeostasis during infection [44].

Data presented herein, as well as those described previously [12], disclose a regulatory circuit involving CRPcAMP, EnvZ/OmpR, and a set of porins in $Y$. pestis (Figure 1). Noticeable remodeling was observed when this regulatory circuit was compared to the counterpart in E. coli (Figure 1). The Y. pestis CRP-cAMP or EnvZ/ OmpR has shown a very high homology to the orthologous one in E. coli (data not shown), and CRP [16] or OmpR [12] from these two bacteria share an identical consensus sequence, indicating that conserved signals recognized by CRP or OmpR are shared by these bacteria. However, the promoter regions of $c r p$ and $o m p R$, $C, F$, and $X$ have undergone genetic variations between E. coli and $Y$. pestis, thereby promoting relevant target genes to split from or integrate into the CRP or OmpR regulon of $Y$. pestis relative to that of $E$. coli. The complex regulatory circuit of porins may contribute to bacterial adaptation to the hosts.

\section{Conclusion}

$Y$. pestis CRP-cAMP has no regulatory effect on the ompR-envZ operon, although it stimulates ompC and $o m p F$ directly, while repressesing $\operatorname{omp} X$ at the same time. This is different from the fact that CRP-cAMP regulates ompR-envZ directly in E. coli and further controls the porin production indirectly through its direct action on ompR-envZ. No transcriptional regulatory association between CRP and its own gene can be detected in $Y$. pestis, which is also in contrast to the observation that CRP acts as both repressor and activator for its own gene in E. coli.

\section{Additional material}

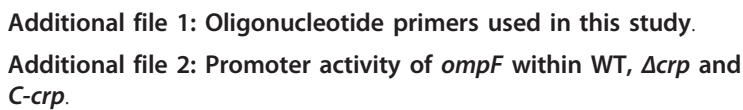

\section{Acknowledgements}

Financial support for this work came from the National Natural Science Foundation of China (30930001, 30900823, and 30771179) and the 973
Program (2009CB522600). The English writing of the manuscript was polished by EnPapers.

\section{Author details}

${ }^{1}$ State Key Laboratory of Pathogen and Biosecurity, Beijing Institute of Microbiology and Epidemiology, Beijing 100071, PR China. ²Department of Biochemistry and Molecular Biology, Jiangsu University School of Medical Technology, Zhenjiang, Jiangsu 212013, PR China.

\section{Authors' contributions}

DZ and RY conceived the study and designed the experiments. HG and YZ performed all the experiments. $L Y, X L$, and $Z G$ contributed to RT-PCR, primer extension assay and DNA binding assays. $Z G$ and $Y T$ participated in protein expression and purification. DZ, XH, and YH performed computational analysis and figure construction. The manuscript was written by DZ and $H G$, and was revised by RY. All the authors read and approved the final manuscript.

Received: 11 June 2010 Accepted: 23 February 2011

Published: 23 February 2011

\section{References}

1. Kawaji H, Mizuno T, Mizushima S: Influence of molecular size and osmolarity of sugars and dextrans on the synthesis of outer membrane proteins 0-8 and O-9 of Escherichia coli K-12. J Bacteriol 1979, 140(3):843-847.

2. Bergstrom LC, Qin L, Harlocker SL, Egger LA, Inouye M: Hierarchical and co-operative binding of OmpR to a fusion construct containing the ompC and ompF upstream regulatory sequences of Escherichia coli. Genes Cells 1998, 3(12):777-788.

3. Nikaido $\mathrm{H}$ : Molecular basis of bacterial outer membrane permeability revisited. Microbiol Mol Biol Rev 2003, 67(4):593-656.

4. Stoorvogel J, van Bussel MJ, Tommassen J, van de Klundert JA: Molecular characterization of an Enterobacter cloacae outer membrane protein (OmpX). J Bacteriol 1991, 173(1):156-160.

5. Dupont M, De E, Chollet R, Chevalier J, Pages JM: Enterobacter aerogenes OmpX, a cation-selective channel mar- and osmo-regulated. FEBS Lett 2004, 569(1-3):27-30.

6. Stoorvogel J, van Bussel MJ, van de Klundert JA: Biological characterization of an Enterobacter cloacae outer membrane protein (OmpX). J Bacteriol 1991, 173(1):161-167

7. Yoshida T, Qin L, Egger LA, Inouye M: Transcription regulation of ompF and ompC by a single transcription factor, OmpR. J Biol Chem 2006, 281(25):17114-17123.

8. Scott NW, Harwood CR: Studies on the influence of the cyclic AMP system on major outer membrane proteins of Escherichia coli K12. FEMS Microbiol Lett 1980, 9:95-98.

9. Dorrell N, Li SR, Everest PH, Dougan G, Wren BW: Construction and characterisation of a Yersinia enterocolitica O:8 ompR mutant. FEMS Microbiol Lett 1998, 165(1):145-151.

10. Brzostek K, Raczkowska A, Zasada A: The osmotic regulator OmpR is involved in the response of Yersinia enterocolitica 0:9 to environmental stresses and survival within macrophages. FEMS Microbiol Lett 2003, 228(2):265-271.

11. Flamez C, Ricard I, Arafah S, Simonet M, Marceau M: Phenotypic analysis of Yersinia pseudotuberculosis 32777 response regulator mutants: new insights into two-component system regulon plasticity in bacteria. Int J Med Microbiol 2008, 298(3-4):193-207.

12. Gao H, Zhang Y, Han Y, Yang L, Liu X, Guo Z, Tang Y, Huang X, Zhou D, Yang R: Phenotypic and transcriptional analysis of the osmotic regulator OmpR in Yersinia pestis. BMC Microbiol 2011, 11:39.

13. Harman JG: Allosteric regulation of the CAMP receptor protein. Biochim Biophys Acta 2001, 1547(1):1-17

14. Busby S, Ebright RH: Transcription activation by catabolite activator protein (CAP). J Mol Biol 1999, 293(2):199-213.

15. Huang $L$, Tsui $P$, Freundlich M: Positive and negative control of ompB transcription in Escherichia coli by cyclic AMP and the cyclic AMP receptor protein. J Bacteriol 1992, 174(3):664-670.

16. Zhan L, Han Y, Yang L, Geng J, Li Y, Gao H, Guo Z, Fan W, Li G, Zhang L, et al: The cyclic AMP receptor protein, CRP, is required for both virulence and expression of the minimal CRP regulon in Yersinia pestis biovar microtus. Infect Immun 2008, 76(11):5028-5037. 
17. Sun W, Roland KL, Kuang X, Branger CG, Curtiss R: Yersinia pestis with regulated delayed attenuation as a vaccine candidate to induce protective immunity against plague. Infect Immun 2010 78(3):1304-1313

18. Kim TJ, Chauhan S, Motin VL, Goh EB, Igo MM, Young GM: Direct transcriptional control of the plasminogen activator gene of Yersinia pestis by the cyclic AMP receptor protein. J Bacteriol 2007, 189(24):8890-8900

19. Sebbane F, Jarrett CO, Gardner D, Long D, Hinnebusch BJ: Role of the Yersinia pestis plasminogen activator in the incidence of distinct septicemic and bubonic forms of flea-borne plague. Proceedings of the National Academy of Sciences of the United States of America 2006, 103(14):5526-5530.

20. Lathem WW, Price PA, Miller VL, Goldman WE: A plasminogen-activating protease specifically controls the development of primary pneumonic plague. Science 2007, 315(5811):509-513.

21. Zhan L, Yang L, Zhou L, Li Y, Gao H, Guo Z, Zhang L, Qin C, Zhou D, Yang R: Direct and negative regulation of the sycO-ypkA-ypoJ operon by cyclic AMP receptor protein (CRP) in Yersinia pestis. BMC Microbiol 2009, 9:178.

22. Zhou D, Tong Z, Song Y, Han Y, Pei D, Pang X, Zhai J, Li M, Cui B, Qi Z, et al: Genetics of metabolic variations between Yersinia pestis biovars and the proposal of a new biovar, microtus. J Bacteriol 2004, 186(15):5147-5152.

23. Deng W, Burland V, Plunkett G, Boutin A, Mayhew GF, Liss P, Perna NT, Rose DJ, Mau B, Zhou S, et al: Genome sequence of Yersinia pestis KIM. J Bacteriol 2002, 184(16):4601-4611.

24. Straley SC, Bowmer WS: Virulence genes regulated at the transcriptional level by $\mathrm{Ca} 2+$ in Yersinia pestis include structural genes for outer membrane proteins. Infect Immun 1986, 51(2):445-454.

25. Han Y, Zhou D, Pang X, Zhang L, Song Y, Tong Z, Bao J, Dai E, Wang J, Guo Z, et al: Comparative transcriptome analysis of Yersinia pestis in response to hyperosmotic and high-salinity stress. Res Microbiol 2005, 156(3):403-415.

26. El-Robh MS, Busby SJ: The Escherichia coli cAMP receptor protein bound at a single target can activate transcription initiation at divergent promoters: a systematic study that exploits new promoter probe plasmids. Biochem J 2002, 368(Pt 3):835-843.

27. van Helden J: Regulatory sequence analysis tools. Nucleic Acids Res 2003, 31(13):3593-3596.

28. Hagiwara D, Sugiura M, Oshima T, Mori H, Aiba H, Yamashino T, Mizuno T: Genome-wide analyses revealing a signaling network of the RcsC-YojNRcsB phosphorelay system in Escherichia coli. J Bacteriol 2003, 185(19):5735-5746

29. Ishizuka H, Horinouchi S, Kieser HM, Hopwood DA, Beppu T: A putative two-component regulatory system involved in secondary metabolism in Streptomyces spp. J Bacterio/ 1992, 174(23):7585-7594

30. Inada T, Takahashi H, Mizuno T, Aiba H: Down regulation of cAMP production by CAMP receptor protein in Escherichia coli: an assessment of the contributions of transcriptional and posttranscriptional control of adenylate cyclase. Mol Gen Genet 1996, 253(1-2):198-204.

31. Igarashi K, Hanamura A, Makino K, Aiba H, Aiba H, Mizuno T, Nakata A Ishihama A: Functional map of the alpha subunit of Escherichia coli RNA polymerase: two modes of transcription activation by positive factors. Proc Natl Acad Sci USA 1991, 88(20):8958-8962.

32. Tagami H, Inada $T$, Kunimura $T$, Aiba H: Glucose lowers CRP* levels resulting in repression of the lac operon in cells lacking CAMP. Mol Microbiol 1995, 17(2):251-258.

33. Balsalobre C, Johansson J, Uhlin BE: Cyclic AMP-dependent osmoregulation of crp gene expression in Escherichia coli. J Bacteriol 2006, 188(16):5935-5944.

34. Ishizuka $H$, Hanamura $A$, Kunimura $T$, Aiba $H$ : A lowered concentration of CAMP receptor protein caused by glucose is an important determinant for catabolite repression in Escherichia coli. Mol Microbiol 1993, 10(2):341-350

35. Papenfort K, Pfeiffer V, Lucchini S, Sonawane A, Hinton JC, Vogel J: Systematic deletion of Salmonella small RNA genes identifies CyaR, a conserved CRP-dependent riboregulator of OmpX synthesis. Mol Microbiol 2008, 68(4):890-906

36. Johansen J, Eriksen M, Kallipolitis B, Valentin-Hansen P: Down-regulation of outer membrane proteins by noncoding RNAs: unraveling the CAMP-
CRP- and sigmaE-dependent CyaR-ompX regulatory case. J Mol Biol 2008, 383(1):1-9.

37. De Lay N, Gottesman S: The Crp-activated small noncoding regulatory RNA CyaR (RyeE) links nutritional status to group behavior. J Bacterio 2009, 191(2):461-476.

38. $\mathrm{Xu}$ J, Johnson RC: Cyclic AMP receptor protein functions as a repressor of the osmotically inducible promoter proP P1 in Escherichia coli. $J$ Bacteriol 1997, 179(7):2410-2417.

39. Landis $L, X u$ J, Johnson RC: The cAMP receptor protein CRP can function as an osmoregulator of transcription in Escherichia coli. Genes Dev 1999, 13(23):3081-3091.

40. McLeod SM, Xu J, Johnson RC: Coactivation of the RpoS-dependent proP P2 promoter by fis and cyclic AMP receptor protein. J Bacteriol 2000, 182(15):4180-4187.

41. Sainz T, Perez J, Villaseca J, Hernandez U, Eslava C, Mendoza G, Wacher C: Survival to different acid challenges and outer membrane protein profiles of pathogenic Escherichia coli strains isolated from pozol, a Mexican typical maize fermented food. Int J Food Microbiol 2005, 105(3):357-367.

42. Cathelyn JS, Crosby SD, Lathem WW, Goldman WE, Miller VL: RovA, a global regulator of Yersinia pestis, specifically required for bubonic plague. Proc Natl Acad Sci USA 2006, 103(36):13514-13519.

43. Harari $\mathrm{O}$, del Val $\mathrm{C}$, Romero-Zaliz R, Shin D, Huang H, Groisman EA, Zwir I: Identifying promoter features of co-regulated genes with similar network motifs. BMC Bioinformatics 2009, 10(Suppl 4):S1.

44. Zhou D, Yang R: Molecular Darwinian evolution of virulence in Yersinia pestis. Infect Immun 2009, 77(6):2242-2250.

doi:10.1186/1471-2180-11-40

Cite this article as: Gao et al:: Regulatory effects of cAMP receptor protein (CRP) on porin genes and its own gene in Yersinia pestis. BMC Microbiology 2011 11:40.

\section{Submit your next manuscript to BioMed Central and take full advantage of:}

- Convenient online submission

- Thorough peer review

- No space constraints or color figure charges

- Immediate publication on acceptance

- Inclusion in PubMed, CAS, Scopus and Google Scholar

- Research which is freely available for redistribution
C Biomed Central 